\title{
MSAS Global Distress Index
}

National Cancer Institute

\section{Source}

National Cancer Institute. MSAS Global Distress Index. NCI Thesaurus. Code C125362.

A subscale of the Memorial Symptom Assessment Scale that measures overall symptom distress. 